\title{
Liver Transplantation as Ultimate Tool to Treat Portal Hypertension
}

\author{
J. Klupp S. Kohler A. Pascher P. Neuhaus \\ Charité, Campus Virchow Clinic, Berlin, Germany
}

\section{Key Words}

Portal hypertension - Liver transplantation - Portal thrombosis · Hepatopulmonary syndrome · Pulmonary hypertension

\begin{abstract}
Portal hypertension is a complication of liver cirrhosis that may itself cause complications such as variceal bleeding, ascites and hepatorenal syndrome. There are several options for symptomatic treatment including drug therapy, endoscopy, transjugular intrahepatic portosystemic shunt (TIPS), and various surgical procedures, notably liver transplantation, the only causal treatment. The indication for liver transplantation has to be defined carefully. Progression of the primary disease, evaluation of comorbidity and overall prognosis have to be considered. Conservative symptomatic treatment is used for bridging purposes until liver transplantation can be provided to cure portal hypertension and the underlying primary disease. Careful timing of the transplantation is necessary as well as reorganization of the waiting lists by introducing new priority systems as the Model for End-Stage Liver Disease (MELD) in order to reduce mortality. Furthermore, living donor liver transplantation and split liver transplantation are methods to enlarge the donor pool, and thus accessibility of transplantation to a greater number of patients. This review evaluates the indication of liver transplantation in the treatment of portal hypertension.
\end{abstract}

Copyright (C) 2005 S. Karger AG, Basel
(C) 2005 S. Karger AG, Basel

0257-2753/05/0231-0065\$22.00/0

Fax +4161306 1234

E-Mail karger@karger.ch

www.karger.com
Accessible online at: www.karger.com/ddi

\section{Introduction}

A variety of liver diseases may cause portal hypertension, an entity that causes complications per se, such as variceal bleeding, ascites, and hepatic encephalopathy. Complications of portal hypertension can be managed by several therapeutic options like drug therapy, interventional endoscopy, transjugular intrahepatic portosystemic shunt (TIPS), or surgical shunt- and non-shunt procedures. In the acute state, the patient has to be treated according to his or her condition, e.g. gastrointestinal bleeding or spontaneous bacterial peritonitis. In advanced disease, liver transplantation is very often the only definitive causal therapy, which cures portal hypertension and most of its complications as well as the underlying liver disease.

Portal hypertension is defined as an increase of 5$10 \mathrm{~mm} \mathrm{Hg}$ above normal portal vein pressure and may be classified as presinusoidal, sinusoidal, and postsinusoidal (table 1) [1]. It is initiated by the increase in resistance of portal blood flow, and is then sustained by the increase in portal blood flow and hyperdynamic systemic circulation. This cascade is triggered by several neurohumoral and paracrine substances such as nitric oxide (NO), prostacyclin $\left(\mathrm{PGI}_{2}\right)$, overactivity of the sympathetic nervous system, $\beta_{2}$-adrenergic receptor agonists, certain neuropeptides, glucagon, and products of tissue hypoxia [2]. These mediators cause peripheral vasodilation and thereby increase the splanchnic blood flow and constitute the 'forward' component of portal hypertension [3]. 
Because of this increased blood flow and the increased portal pressure, collaterals are formed such as the short gastro-splenic veins and esophageal varices [1].

\section{Complications of Portal Hypertension}

Complications of portal hypertension develop independently of the underlying liver disease, and consist mainly of gastrointestinal bleeding, i.e. bleeding of esophageal varices, ascites, hepatic encephalopathy, hepatorenal syndrome, portopulmonary hypertension, and hepatopulmonary syndrome.

In portal hypertension, collaterals are formed to decompress the portal system. Collateralization is accompanied by an intensified splanchnic vasodilation due to a hyperdynamic circulation, resulting in an increase in portal venous inflow [4]. Esophageal varices, representing the clinically most relevant portosystemic collaterals, affect about $50 \%$ of patients with newly diagnosed liver cirrhosis [5]. In the case of portal hypertension $>12 \mathrm{~mm}$ $\mathrm{Hg}$, the incidence of variceal bleeding is increasing and affects $30 \%$ of patients with compensated liver disease and up to $60 \%$ of patients with decompensated liver disease [6].

Ascites formation is multifactorial: increased lymphatic flow, a neurogenic hepatorenal reflex, and a decrease in effective arterial blood volume because of splanchnic arterial vasodilation [7] leads to an increase in renal sodium and water retention by activation of the sympathetic nervous system and renin-angiotensin-aldosterone system [8]. Thereby, total body water increases and, in severe cases, dilutional hyponatremia occurs [9]. Water excretion can be further impaired by several factors including diuretics, nonsteroidal anti-inflammatory drugs (NSAIDs), large volume paracentesis performed without plasma expansion and the use of vasopressin analogues during treatment of variceal bleeding [7]. In addition, the filtration rate to the ascending limb of the loop of Henle is reduced, $\mathrm{ADH}$ secretion is increased and the renal synthesis of prostaglandins is reduced [9].

Splanchnic vasodilation and loss of effective arterial blood volume lead to renal hypoperfusion and subsequently to progressive activation of vasoconstrictor systems as the renin-angiotensin-aldosterone system and the sympathetic nervous system [7]. Vasoconstriction of the renal cortex leads to reduced renal blood flow and glomerular filtration rate, causing hepatorenal syndrome [10]. There are two types of hepatorenal syndrome: type 1 is characterized by a rapid progression of renal failure with a twofold increase in initial serum creatinine or a $50 \%$ reduction of initial 24-hour creatinine clearance to below $20 \mathrm{ml} / \mathrm{min}$ in less than 2 weeks, whereas type 2 develops more moderately without fulfilling the criteria of type 1 [7]. Portopulmonary hypertension is defined as raised pulmonary arterial pressure of greater than $25 \mathrm{~mm}$ $\mathrm{Hg}$ at rest [11]. High cardiac output and hyperdynamic circulation in patients with portal hypertension increase shear stress on the pulmonary circulation. By this, vasoconstriction leads to increased vascular resistance and to progressive pulmonary vascular remodeling due to proliferation of pulmonary arterial endothelial cells and smooth muscle cells, which result in pulmonary hypertension [12]. Patients mainly suffer from progressive dyspnea, less frequently from fatigue, palpitations, syncope, or chest pain [12].

In hepatopulmonary syndrome, hyperdynamic circulation and portal hypertension lead to altered bowel perfusion and an increased rate of enteral translocation of gram-negative bacteria and endotoxin, which stimulate the release of vasoactive mediators, including TNF- $\alpha$, hem-oxygenase-derived carbon monoxide, and NO [12]. This causes abnormal intrapulmonary dilation and shunting. Patients eventually suffer from progressive hypoxemia with increasing cyanosis. Some patients may develop clubbing, and cutaneous telangiectasis (spider angiomas) are frequently present [12].

\section{Options for Treatment prior to Liver Transplantation}

Depending on the severity of liver disease causing portal hypertension and on the main complications caused by portal hypertension, there are several options to treat portal hypertension and its complications prior to liver transplantation.

Drug therapy mainly consists of nonselective $\beta$-blockers in order to reduce portal venous pressure [13]. If no reduction of hepatic venous pressure gradient of $>20 \%$ or $<12 \mathrm{~mm} \mathrm{Hg}$ is achieved, $\beta$-blockers can be combined with isosorbide mononitrate [14]. In the case of acute bleeding, terlipressin, a vasopressin analogue, can be used as an effective agent to control variceal bleeding [15]. Vasoactive drugs should be given immediately and maintained for 5 days, and should be combined with initial endoscopic treatment [16]. Recommendations for ascites treatment include both spironolactone and furosemide up to a daily dose of 400 and $160 \mathrm{mg}$, respectively [10]. In long-term ascites therapy, doses of diuretics have to be limited to 
avoid prerenal renal failure. In addition, periodic paracentesis alongside the administration of human albumin ( $50 \mathrm{ml}$ of $25 \%$ albumin solution for every 1.5 liters removed) is advocated [17]. In the case of acute deterioration of kidney function due to acute exacerbation of liver disease or failure of diuretic therapy, dopamine infusions in combination with plasma expanders can be used. Continuous intravenous administration of epoprostenol shows good results for primary therapy of portopulmonary hypertension. In an experimental setting, the endothelin-receptor antagonist bosentan demonstrated beneficial effects on hemodynamics and exercise capacity in patients with portopulmonary hypertension. However, due to its hepatotoxic potential, it has not yet been approved for clinical use in patients with liver diseases [12].

If variceal bleeding occurs, interventional endoscopy is the treatment of choice. This includes sclerotherapy, application of tissue adhesives, banding of varices, and some other methods. Variceal banding is more difficult in acute bleeding due to less visibility, but can control bleeding as effectively as sclerotherapy with less complications and thus seems to improve survival compared to sclerotherapy [6].

Since the end of the 1980s, TIPS has become a standard option to reduce portal pressure when conservative treatment has failed [18]. Morbidity and mortality have decreased in contrast to surgery and the reduction in portal hypertension and thereby the incidence of side effects, i.e. hepatic encephalopathy and liver failure, can be adjusted more precisely by varying stent diameter, ranging from 7 to $12 \mathrm{~mm}$ [19]. Furthermore, in the case of inappropriate shunt flow, TIPS function can be optimized by a repetitive procedure. TIPS can be used either as an emergency therapy in case of uncontrollable variceal bleeding, or as an elective procedure in patients with complications due to portal hypertension such as refractory ascites and hepatorenal syndrome [19]. Also, there are several reports of transjugular portosystemic shunting that led to the correction of hypoxemia in case of hepatopulmonary syndrome [20]. The direct impact of TIPS on liver transplantation, perioperative outcome, and rate of complications has not been fully evaluated yet. There are some reports of technical difficulty due to incorrect positioning of the stent and damage to the portal vein intima, dislocation of the stent into the portal vein [21], and injury to the bile duct [22]. However, a TIPS placed correctly does not influence the liver transplantation procedure and may serve to bridge the interval to liver transplantation as well as a solution for patients not awaiting liver transplantation [23].

Liver Transplantation as Ultimate Tool to Treat Portal Hypertension
If the insertion of a TIPS is technically not possible, a surgical shunt would be the next line of treatment. Total portosystemic shunts include any shunt with a diameter greater than $10 \mathrm{~mm}$, and control variceal bleeding and ascites in up to $90 \%$ of patients $[24,25]$. Because of the large shunt diameter, portal flow is diverted through the shunt leading to decompression of sinusoids with a relatively high risk of liver failure and encephalopathy, however [24,25]. Partial portosystemic shunts reduce the size of the anastomosis of a side-to-side shunt to $8 \mathrm{~mm}$. Up to this size, portal pressure is reduced to $12 \mathrm{~mm} \mathrm{Hg}$ and portal flow is maintained in $80 \%$ of patients [26]. Selective shunts provide decompression of gastroesophageal varices to control bleeding, while, at the same time, portal hypertension and thus portal flow to the cirrhotic liver are maintained. The distal splenorenal shunt [27], which is most commonly used, combines the anastomosis of the splenic vein to the left renal vein and ligature of the left gastric vein [28]. At present, surgical shunts may be of some value in patients with recurrent variceal bleeding in early or absent liver disease, such as portal vein thrombosis [29]. A previous portosystemic shunt operation is no contraindication to subsequent liver transplantation, although peritransplant morbidity is increased due to the increased complexity of the procedure, portal vein abnormalities, and adhesions [30]. When a surgical shunt is indicated, a distal splenorenal shunt seems to be superior to other shunts to control variceal bleeding and does not significantly compromise future liver transplantation. However, the incidence of postoperative portal vein thrombosis of up to $6 \%$ should be taken into consideration [31].

When shunt procedures, either interventional or surgical, are technically impossible, non-shunt operations may be indicated. They comprise devascularization operations including gastric and esophageal devascularization, mostly splenectomy, to reduce a major inflow path of gastroesophageal varices, and in some instances esophageal transection [32]. The incidence of liver failure and hepatic encephalopathy is low following devascularization procedures due to a better maintenance of portal flow, but portal vein thrombosis occurs in up to $20 \%$ of patients after splenectomy [28].

\section{Liver Transplantation}

All therapeutic options listed above, with some restrictions regarding surgical non-shunt procedures, maybe used prior to liver transplantation. However, in most

Dig Dis 2005;23:65-71 
Table 1. Classification of portal hypertension

\begin{tabular}{l}
\hline Presinusoidal \\
Extrahepatic \\
Portal vein thrombosis \\
Intrahepatic \\
Schistosomiasis \\
Idiopathic portal hypertension \\
Congenital hepatic fibrosis \\
Sarcoidosis \\
$\quad$ Felty's syndrome \\
$\quad$ Primary biliary cirrhosis \\
\hline Sinusoidal \\
Alcoholic cirrhosis \\
Nonalcoholic cirrhosis \\
Nodular regenerative hyperplasia \\
\hline Postsinusoidal \\
Extrahepatic \\
Budd Chiari syndrome \\
Intrahepatic \\
Veno-occlusive disease \\
Central hyaline sclerosis (alcohol hepatitis) \\
\hline
\end{tabular}

cases liver transplantation is the only causal treatment for portal hypertension and also cures the underlying liver disease. While treating the patient conservatively, the optimal time point for placing the patient on the waiting list should not be missed, in particular with regard to increasing waiting time and higher perioperative morbidity and mortality after liver transplantation in advanced liver failure and hepatorenal syndrome [8, 33]. Furthermore, some complications of portal hypertension, such as severe, fixed pulmonary hypertension, are contraindications to liver transplantation [34].

Without the option of liver transplantation, 5-year survival of patients with Child $\mathrm{C}$ cirrhosis and variceal bleeding is approximately $25 \%$ whereas after liver transplantation it is 70-75\% [35]. Even in patients with a Child-Turcotte-Pugh (CTP) score below 10, 5-year survival after liver transplantation is better than without ( 85 vs. $73 \%$, respectively) (table 1) [31]. However, due to the shortage of donor organs, not every patient with portal hypertension can receive a liver graft in time, and mortality on the waiting list is increasing [28].

Indication and time point for liver transplantation have to be evaluated carefully, considering not only etiology, severity, and activity of underlying liver disease, but also comorbidity and possible contraindications [36]. A widely used clinical scoring system is the Child score or one of its modifications, e.g. CTP classification (table 2).
Table 2. Child-Turcotte-Pugh classification

\begin{tabular}{llll}
\hline Parameters & \multicolumn{2}{l}{ Points } & 3 \\
\cline { 2 - 4 } & 1 & 2 & moderate \\
& no & few & grade 3-4 \\
Ascites & no & grade 1-2 & $>3$ \\
Encephalopathy & $<2$ & $2-3$ & $>2.8$ \\
Bilirubin, mg/dl & $>3.5$ & $2.8-3.5$ & $<30$ \\
Serum albumin, g/d & $>50$ & $30-50$ & \\
Quick, \% & Points & \\
Class & $3-6$ & & \\
\hline A & $7-9$ & & \\
B & $10-15$ & & \\
C & & & \\
\hline
\end{tabular}

Since the prognostic value of the CTP score has never been proven [37] and because this score contains subjective values, such as degree of encephalopathy and ascites, the Model for End-Stage Liver Disease (MELD) has been developed [38]. The United Network for Organ Sharing (UNOS) has been using this score to organize waiting list priority since February 27, 2002. Originally, the MELD score was developed to determine the short-term prognosis of patients undergoing a TIPS procedure based on four variables: serum creatinine, serum bilirubin, international normalized ratio (INR), and the etiology of liver disease. It was demonstrated that implication of the etiology of liver disease into the calculation of the score contributes very little to the ability of MELD score to predict 3-month survival. Therefore, the Organ Procurement and Transplantation Network (OPTN) calculates the MELD score using the following equation:

$\mathrm{MELD}=0.957 \times \mathrm{LN}($ creatinine $)+0.378 \times \mathrm{LN}$ (bilirubin $)+$ $1.12 \times \mathrm{LN}(\mathrm{INR})+0.643$.

The score is rounded and truncated for values of 40 and higher. This new system does not categorize patients into groups but utilizes a continuous score. The predictive value for 3-month survival is excellent, and superior to that of the CTP score. Patients with an MELD score of $<9$ have a 3-month mortality rate of 1.9 versus $71.3 \%$ for patients with an MELD score $>40$ [39].

Indications to liver transplantation for some complications of portal hypertension as hepatorenal syndrome and pulmonary hypertension have to be discussed separately. Pulmonary hypertension might be reversible after liver transplantation, but if severe, fixed pulmonary hypertension (MPAP $>35 \mathrm{~mm} \mathrm{Hg}$ ) is present, mortality is unacceptably high and thus liver transplantation is con- 
traindicated. In patients with mild or moderate pulmonary hypertension data suggest that postoperative morbidity is unaffected [40].

If refractory hepatorenal syndrome with elevated serum creatinine levels occurs, all efforts should be made to normalize serum creatinine as soon as possible after liver transplantation. If the elevation persists at 4 weeks, 3 months and 1 year postoperatively, the risk of developing chronic renal failure or end-stage renal disease increases over time and the odds ratio for development of chronic renal failure is $1.598,2.254$, and 2.583 , respectively [41]. Nephrotoxicity is the most common side effect of calcineurin inhibitors (CNI). Thus CNI-sparing immunosuppressive regimens should be considered in these patients. There are several protocols using mycophenolate-mofetil (MMF), sirolimus or antibody induction therapy in combination with reduced doses of CNIs to avoid renal insufficiency. [41]. Even CNI-free therapeutic regimens are currently under investigation [42].

Besides the reorganization of the waiting lists by scoring the patients according to the severity of disease instead of waiting time (e.g. MELD, ET status), in recent years, living-donor liver transplantation (LDLT) and split liver transplantation have emerged as good alternatives to bridge organ shortage [43]. Apart from donor morbidity, technical problems and small-for-size syndrome (SFSS), a higher risk of re-bleedings was observed after split-liver transplantation compared with full-size organ transplantation [44-46]. Graft weight to recipient body weight ratio (GRBWR) should be close to 1\%. SFSS can cause graft dysfunction characterized by enhanced cholestasis, coagulopathy, and massive ascites production [47]; SFSS is mainly caused by two problems of LDLT, a compromised venous outflow from the posterior segments (V and VIII) and posttransplant portal hyperperfusion and hypertension [49]. Early portal venous pressure in LDLT is strongly associated with poor patient and graft survival [48]. Posttransplant portal hypertension is observed in deceased donor liver transplantation, but is more frequent in LDLT due to reduction in the size of the sinusoidal vascular bed and hyperdynamic circulation. Recipients with a GRBWR $<0.8 \%$ have a significantly lower survival prognosis. Sufficient venous outflow can be achieved by a variety of methods such as preservation of middle hepatic vein or reconstruction of hepatic veins [49]. There are several studies suggesting reduction in portal venous flow by ligation of splenic artery when portal venous flow exceeds $250 \mathrm{ml} / \mathrm{min} / 100 \mathrm{~g}$ liver tissue $[43,47-50]$. The relationship of portal pressure and portal venous flow volume varies with recipient and graft factors, and thus patient and graft survival can be improved either by ligation of splenic artery or reconstruction of hepatic veins [50].

Portal venous thrombosis (PVT), a cause for presinusoidal portal hypertension, is a common complication of hepatic cirrhosis and is observed in $2-19 \%$ of cirrhotic patients undergoing liver transplantation. A higher incidence is found in patients after previous splenectomy [51]. PVT was initially believed to be an absolute contraindication to orthotopic liver transplantation. Despite these early criteria, liver transplantation in patients with PVT is possible provided that hepatopedal flow can be reestablished. There are a variety of different surgical techniques to regain portal vein inflow: While thrombendvenectomy is preferred, the donor portal vein can also be implanted at the splenomesenteric confluence or onto a varix if PVT is restricted to the extrahepatic portal vein [51]. Furthermore, venous grafts can be placed between the graft portal vein and recipient superior mesenteric vein, splenomesenteric confluence, or other mesenteric veins. In these cases, postoperative anticoagulation is recommended. If hepatopedal inflow can be reestablished, the outcome seems to be comparable with that of transplant recipients without previous PVT [51]. In the presence of complete splanchnic thrombosis and intestinal malperfusion, a combined liver-intestine transplantation has been proposed [52]. The long-term effects of arterialization of the portal vein during transplantation are not yet fully investigated, but first results suggest that unphysiologic vascular reconstruction worsens the outcome as compared with thrombendvenectomy [53]. However, there are reports of successfully arterialized portal veins resulting in good long-term outcome. Additionally, this procedure can be used as rescue therapy if portal flow cannot be achieved [54].

LDLT in patients with PVT remains controversial. However, when performed, combination of thrombendvenectomy and a venous jump-graft is required, e.g. recipient saphenous vein or internal iliac vein. Alternatively, cryoconserved grafts can be used. Other techniques already applied in patients with extensive portomesenteric thrombosis include cavo-portal hemitransposition, characterized by an anastomosis of the donor portal vein to the inferior vena cava, which is than ligated cranial to the anastomosis [55]. 


\section{Conclusions}

Liver transplantation is the only curative treatment for patients with portal hypertension in end-stage liver disease. Patients with good liver function despite portal hypertension may be managed satisfactorily without liver transplantation. However, patients with end-stage liver disease should be considered timely for liver transplanta- tion. Patients on the waiting list need symptomatic 'bridging therapy', such as drug therapy, endoscopic therapy, and a TIPS procedure, until a liver transplant is available. Improved waiting list management and alternatives to deceased donor transplantation such as split liver transplantation and LDLT can expand the donor pool and help to decrease the waiting time and thereby the mortality of patients on the waiting list.

\section{References}

-1 Kapoor D, Sarin SK: Pathophysiology of portal hypertension. J Gastroenterol Hepatol 2002; 17:482-487.

$\checkmark 2$ Moreau R, Lebrec D: Endogenous factors involved in the control of arterial tone in cirrhosis. J Hepatol 1995;22:370-376.

$\checkmark 3$ Stanley AJ, Hayes PC: Portal hypertension and variceal haemorrhage. Lancet 1997;350:12351239.

4 Bosch J, Garcia-Pagan JC: Complications of cirrhosis. I. Portal hypertension. J Hepatol 2000;32:141-156.

$>5$ D'Amico G, Pagliaro L, Bosch J: The treatment of portal hypertension: A meta-analytic review. Hepatology 1995;22:332-354.

$\checkmark 6$ Lata J, Hulek P, Vanasek T: Management of acute variceal bleeding. Dig Dis 2003;21:615.

7 Heneghan MA, Harrison PM: Pathogenesis of ascites in cirrhosis and portal hypertension. Med Sci Monit 2000;6:807-816.

$\checkmark 8$ Gentilini P, Vizzutti F, Gentilini A, La Villa G: Ascites and hepatorenal syndrome. Eur J Gastroenterol Hepatol 2001;13:313-316.

$\checkmark 9$ McCullough AJ, Mullen KD, Kalhan SC: Measurements of total body and extracellular water in cirrhotic patients with and without ascites. Hepatology 1991;14:1102-1111.

- 10 Arroyo V, Ginés P, Gerbes AL, Dudley FJ, Gentilini P, Laffi G, Reynolds TB, Ring-Larsen $\mathrm{H}$, Scholmerich J: Definition and diagnostic criteria of refractory ascites and hepatorenal syndrome in cirrhosis. Hepatology 1996;23: 164-176.

11 Rich S: Primary pulmonary hypertension: Executive summary from the World Symposium on Primary Pulmonary Hypertension 1998. Geneva, World Health Organization 1998.

- 12 Hoepper MM, Krowka MJ, Strassburg CP. Portopulmonary hypertension and hepatopulmonary syndrome. Lancet 2004;363:14611468.

13 Bosch J, Abraldes JG, Groszmann P: Current management of portal hypertension. J Hepatol 2003;38:S54-S68.

14 Wiest R, Groszmann R: Nitric oxide and portal hypertension: Its role in the regulation of intrahepatic and splanchnic vascular resistance. Semin Liver Dis 1999; 19:411-426.
15 Boyer TD: Pharmacologic treatment of portal hypertension: Past, present, and future. Hepatology 2001;34:834-839.

16 Burroughs AK, Patch DW: Management of variceal haemorrhage in cirrhotic patients. Gut 2001;48:738-740.

17 Ginés P, Fernandez-Esparrach G, Monescillo A, Vila C, Domenech E, Abecasis R, Angeli P, Ruiz-Del-Arbol L, Planas R, Sola R, Gines P, Terg R, Inglada L, Vaque P, Salerno F, Vargas V, Clemente G, Quer JC, Jimenez W, Arroyo V, Rodes J: Randomized trial comparing albumin, dextran 70, polygeline in cirrhotic patients with ascites treated with paracentesis. Gastroenterology 1996;111:1002-1010.

18 Richter GM, Noeldge G, Palmaz JC, Roessle M, Slegerstetter V, Franke M, Gerok W, Wenz W, Farthman E: Transjugular intrahepatic portacaval stent shunt: Preliminary clinical results. Radiology 1990;174:1027-1030.

19 Roessle M, Grandt D: TIPS: An update. Best Prac Res Clin Gastroenterol 2004; 18:99-123.

20 Lasch HM, Fried MW, Zacks SL, Odell P, Johnson MW, Gerber DA, Sandhu FS, Fair JH, Shrestha R: Use of transjugular intrahepatic portosystemic shunt as a bridge to liver transplantation in a patient with severe hepatopulmonary syndrome. Liver Transpl 2001;7: 147-149.

21 Glanemann M, Mueller AR, Stange B, Steinmueller T, Neuhaus P: Orthotopic liver transplantation in case of TIPS stent dislocation. Zentralbl Chir 2002;127:997-1000.

22 Millis JM, Martin P, Gomes A, Shaked A, Colquhoun SD, Jurim O, Goldstein L, Busuttil RW: Transjugular intrahepatic portosystemic shunts: Impact on liver transplantation. Liver Transpl Surg 1995;1:229-233.

23 Otto G, Datsis K, Richter G, Senninger N, Theilmann L, Herfarth C: Liver transplantation after sugical shunt or transjugular intrahepatic portosystemic shunt. Radiologe 1994;34: 187-190.

24 Stipa S, Balducci G, Ziparo V, Stipa F, Lucandri G: Total shunting and elective management of variceal bleeding. World J Surg 1994; 18:200-204.

25 Bismuth H, Franco D, Hepp J: Portal-systemic shunt in hepatic cirrhosis: Does the type of shunt decisively influence the clinical result? Ann Surg 1974;179:209-218.
26 Sarfeh IJ, Rypins EB, Mason GR: A systemic appraisal of portocaval H-graft diameters. Clinical and hemodynamic perspectives. Ann Surg 1986;204:356-363.

27 Warren WD, Zeppa R, Fomon JJ: Selective trans-splenic decompression of gastroesophageal varices by distal splenorenal shunt. Ann Surg 1967; 166:437-455.

28 Henderson JM: Surgical treatment of portal hypertension. Baillieres Best Pract Res Clin Gastroenterol 2000;14:911-925.

29 Rikkers LF, Jin G, Langnas AN, Shaw BW Jr: Shunt surgery during the era of liver transplantation. Ann Surg 1997;226:51-57.

30 Mazzaferro V, Rodo S, Tzakis AG, Stieber AC, Makowka L, Starzl TE: Liver transplantation in patients with previous portasystemic shunt. Am J Surg 1990;160:111-116.

$>31$ Wood RP, Shaw BW, Rikkers LF: Liver transplantation for variceal hemorrhage. Surg Clin North Am 1990;70:449-461.

-32 Orozco H, Mercado MA, Takahashi T, Hernandez-Ortiz J, Capellan JF, Garcia-Tsao G: Elective treatment of bleeding varices with a Sugiura operation over 10 years. Am J Surg 1992; 163:585-589.

33 Gonwa TA, Klintmalm GB, Levy M, Jennings LS, Goldstein RM, Husberg BS: Impact of pretransplant renal function on survival after liver transplantation. Transplantation 1995; 59: 361-365.

34 Schott R, Chaouat A, Launoy A, Pottecher T, Weitzenblum E: Improvement of pulmonary hypertension after liver transplantation. Chest 1999; 115:1748-1749.

-35 Iwatsuki S, Starzl TE, Todo D, Gordon RD, Tzakis AG, Marsh JW, Makowka L, Koneru B, Stieber A, Klintmalm G, et al: Liver transplantation in the treatment of bleeding esophageal varices. Surgery 1988; 104:697-705.

36 Henderson JM: Liver transplantation for portal hypertension. Gastroenterol Clin North Am 1992;21:192-213.

37 Brown RS Jr, Kumar KS, Russo MW, Kinkhabwala M, Rudow DL, Harren P, Lobritto S, Emond JC: Model for end-stage liver disease and Child-Turcotte-Pugh score as predictors of pretransplantation disease severity, posttransplantation outcome, and resource utilization in United Network for Organ Sharing status 2A patients. Liver Transpl 2002;8:278-284. 
-38 Freeman RB, Wiesner RH, Roberts JP, McDiarmid S, Dykstra DM, Merian RM: Improving liver allocation: MELD and PELD. Am J Transpl 2004;4:114-131.

-39 Wiesner R, Edwards E, Freeman R, Harper A, Kim R, Kamath P, Kremers W, Lake J, Howard T, Merion RM, Wolfe RA, Krom R, et al: Model for end-stage liver disease (MELD) and allocation of donor livers. Gastroenterology 2003;124:91-96.

-40 Starkel P, Vera A, Gunson B, Mutimer D: Outcome of liver transplantation for patients with pulmonary hypertension. Liver Transpl 2002; 8:382-388.

-41 Gonwa TA, Mai ML, Melton LB, Hays SR, Goldstein RM, Levy MF, Klintmalm GB: Endstage renal disease (ESRD) after orthotopic liver transplantation (OLTX) using calcineurin-based immunotherapy. Transplantation 2001;72:1934-1939.

-42 Flechner SM: Minimizing calcineurin inhibitor drugs in renal transplantation. Transplant Proc 2003;35:118-121.

43 Troisi R, Praet M, de Hemptinne B: Small-forsize syndrome: What is the problem? Liver Transpl 2003;9:1.

44 Sato Y, Yamamoto S, Oya H, Nakatsuka H, Tsukahara A, Kobayashi T, Watanabe T, Hatakeyama K: Splenectomy for reduction of excessive portal hypertension after adult living-related donor liver transplantation. Hepatogastoenterology 2002;49:1652-1655.
45 Kiuchi T, Kasahara M, Uryuhara K, Inomata Y, Uemoto S, Asonuma K, Egawa H, Fujita S, Hayashi M, Tanaka K: Impact of graft size mismatching on graft prognosis in liver transplantation from living donors. Transplantation 1999;67:312-327.

46 Hirata M, Kita Y, Harihra Y, Hisatomi S, Sano K, Mizuta K, Yoshino H, Sugawara Y, Takayama T, Kawarasaki H, Hashizume K, Makuuchi M: Gastrointestinal bleeding after livingrelated liver transplantation. Dig Dis Sci 2002; 47:2386-2388.

47 Troisi R, de Hemptinne B: Clinical relevance of adapting portal vein flow in living donor liver transplantation in adult patients. Liver Transpl 2003;9:36-41.

48 Garcia-Valdecasas JC, Fuster J, Charco R, Bombuy E, Fondevila C, Ferrer J, Ayuso C, Taura P: Changes in portal vein flow after adult living-donor liver transplantation: Does it influence postoperative liver function? Liver Transpl 2003;9: 564-569.

-49 Ito T, Kiuchi T, Yamamoto H, Oike F, Ogura Y, Fujimoto Y, Hirohashi K, Tanaka K: Changes in portal venous pressure in the early phase after living-donor liver transplantation: Pathogenesis and clinical implications. Transplantation 2003;75:1313-1317.

50 Troisi R, Cammu G, Militerno G, de Baerdemaeker L, Decruyenaere J, Hoste E, Smeets P, Colle I, van Vlierberghe H, Petrovic M, Voet D, Mortier E, Hesse UJ, de Hemptinne B: Modulation of portal graft inflow: A necessity in adult living-donor liver transplantation? Ann Surg 2003;237:429-436.
51 Molmenti EP, Roodhouse TW, Molmenti H, Jaiswal K, Jung G, Marubashi S, Sanchez EQ, Gogel B, Levy MF, Goldstein RM, Fasola CG, Elliott EE, Bursac N, Mulligan D, Gonwa TA, Klintmalm GB: Thrombendvenectomy for organized portal vein thrombosis at the time of liver transplantation. Ann Surg 2002;235:292296

52 Cherqui D, Duvoux C, Rahmouni A, Rotman N, Dhumeaux D, Julien M, Fagniez PL: Orthotopic liver transplantation in the presence of partial or total portal vein thrombosis: Problems in diagnosis and management. World $\mathrm{J}$ Surg 1993;17:669-674.

53 Ott R, Boehner C, Mueller S, Aigner T, Bussenius-Kammerer M, Yedibela S, Kissler H, Hohenberger W, Reck T, Mueller V: Outcome of patients with pre-existing portal vein thrombosis undergoing arterialization of the portal vein during liver transplantation. Trans Int 2003; 16:15-20.

54 Stange B, Glanemann M, Nuessler NC, Bechstein WO, Neuhaus P, Settmacher U: Indication, technique, and outcome of portal vein arterialization in orthotopic liver transplantation. Transplant Proc 2001;33:14141415

-55 Kadry Z, Selzner N, Handschin A, Muellhaupt B, Renner EL, Clavien PA: Living donor liver transplantation in patients with portal vein thrombosis: A survey and review of technical issues. Transplantation 2002;74:696-701. 